\title{
Multidrug-resistant pathogens and their plasmid curing by lactic acid bacteria
}

Kiran, Amanpreet Kaur and Wamik Azmi*

Department of Biotechnology, Himachal Pradesh University, Summerhill, Shimla-171005, Himachal Pradesh, India

\begin{tabular}{|c|c|}
\hline Article Info & Abstract \\
\hline $\begin{array}{l}\text { Article history } \\
\text { Received } 10 \text { September } 2021 \\
\text { Revised } 29 \text { October } 2021 \\
\text { Accepted } 30 \text { October } 2021 \\
\text { Published Online } 30 \text { December } 2021\end{array}$ & $\begin{array}{l}\text { Antibiotics are used to treat and prevent infections, but the overuse of drugs makes the microorganisms } \\
\text { drug resistant, and with the time they become resistant to more than one drug. These bacteria are known } \\
\text { as multidrug-resistant bacteria. Resistivity of bacteria against the antibiotics makes them more hazardous } \\
\text { for human beings and animals too and those bacterial infections become untreatable and lead to death of } \\
\text { the person. The resistivity to bacteria is provided by the bacterial plasmids, which contains antibiotic } \\
\text { resistant genes. This problem can be overcome by removing bacterial plasmids from the bacterial cells. }\end{array}$ \\
\hline $\begin{array}{l}\text { Keywords } \\
\text { Antibiotics } \\
\text { Pathogens } \\
\text { Multidrug resistant } \\
\text { Lactic acid bacteria } \\
\text { Plasmid curing }\end{array}$ & $\begin{array}{l}\text { This can be done by treatment with plasmid curing agents, but various plasmid curing agents such as } \\
\text { acridine orange or SDS are toxic and mutagenic in nature. Various investigations have been undertaken to } \\
\text { determine the antibacterial effect and plasmid curing ability of extracellular and intracellular extracts of } \\
\text { lactic acid bacteria (LAB) to cure plasmids of antibiotic resistant bacterial isolates. The microtiter plate } \\
\text { method was used to determine the minimum inhibitory concentration of LAB extracts. Plasmid curing } \\
\text { mediated by LAB extracts resulted in the loss of antibiotics resistance encoded in plasmids, as well as the } \\
\text { antibiotics resistance profile of cured strains. The extracellular extracts of LAB were considered a natural } \\
\text { and harmless source to combat plasmid borne multidrug-resistant bacteria. }\end{array}$ \\
\hline
\end{tabular}

\section{Introduction}

Bacteria are the type of biological cells that constitutes a large domain of prokaryotic microorganisms. The earliest life on land may have been bacteria. They are living on land since 3.22 billion years ago (Homann, 2018). The vast majority of bacteria in the body are beneficial, particularly in the gut flora. However, several species of bacteria are pathogenic and cause infectious diseases, including cholera, syphilis, anthrax, leprosy, bubonic plaque. Antibiotics play a vital role in fighting against the microorganisms and they are probably one of the most successful forms of chemotherapy in the history of medicine (Rustam et al., 2010). Current antibiotics, some of them are heavily modified that target the same cellular processes as their natural or synthetic predecessors. The range of these targets is limited to the components of translational machinery, cell wall biosynthesis, DNA/RNA metabolism and some other cellular processes. After the genome sequencing, it becomes easy to implement the idea of a magic bullet in a more elaborate way, so that the targets defined much more precisely at the molecular level. This idea helps in the availability of chemically diverse compound collections to screen for the target/drug combination (Payne et al., 2007). However, robust evidence has shown that exposure to antibiotics does offer benefits for patients but can also cause gastrointestinal symptoms, rash and increases the probability of selection for resistant commensal bacteria (Gloria, 2021). Drug resistance traits in bacteria are rapidly spreading by horizontal

\section{Corresponding author: Dr. Wamik Azmi}

Professor, Department of Biotechnology, Himachal Pradesh University, Summerhill, Shimla-171005, Himachal Pradesh, India

E-mail: wamikazmi@rediffmail.com

Tel.: +91-9418311183

Copyright (c) 2021 Ukaaz Publications. All rights reserved.

Email: ukaaz@yahoo.com; Website: www.ukaazpublications.com gene transfer, especially through plasmids. Plasmid curing agents that are active both in vitro and in vivo will resensitize to reduce the burden of antibiotic resistance (Subhashree et al., 2019).

\section{Antibiotic resistant}

With the vast use of antibiotic, resistance developed by microorganisms become more prevalent and their use is currently under threat (Junaid Ali et al., 2018). As the antibiotic resistant increasing drastically, it is essential to examine the key socioeconomic factors which contribute to the rise in the prevalence of antibiotic resistance in developing and developed nations. Although, it is difficult to get accurate estimates of drug resistance, it is predicted that antimicrobial-resistant infections will lead to nearly 10 million deaths per year by 2050 and a total GDP loss of $\$ 100.2$ trillion by 2050 , if appropriate actions are not taken (O'Neill, 2014).

\section{Causes of antibiotic resistant}

Microbes undergo mutation; some of the mutations may help an individual microbe survive after the exposure to an antimicrobial agent. During conjugation, microbes get genes from each other, including genes that make the microbe drug resistant. Due to this, sensitive bacteria also become drug resistant. Antibiotics may influence this process by inducing the transmission of resistance elements; these antimicrobials may additionally exert a selective pressure to the emergence of resistance (Stokes and Gilling, 2011; Munita and Arais et al., 2016). Antibiotic resistance among pathogenic bacteria, many also be due to include inadequate regulations and awareness deficiency in the use of antibiotics. Overuse of antibiotics in poultry and livestock promote the antibiotic resistant, rather than to control infection (Bartlett et al., 2013; Spellberg and Gilbert, 2014). 


\section{Multidrug resistance}

Multidrug-resistance (MDR) is defined as insensitivity of a microorganism to the antimicrobial medicines (which are structurally unrelated and have different molecular targets) despite earlier sensitivity to it (Singh, 2013; Popêda et al., 2014). According to WHO, these resistant microorganisms (like bacteria, fungi, viruses, and parasites) are able to conflict with antimicrobial drugs, which leads to ineffective treatment, resulting in persistence and spreading of infections. Although, the development of MDR is a natural phenomenon, vast increase in the number of immune-compromised diseases, like diabetic patients, HIV-infected individuals who have undergone organ transplantation, and severe burn patients, makes the body an easy target for hospital acquired infectious diseases, thereby contributing to further spread of MDR (Nikaido, 2009; WHO, 2014). Multidrug-resistance is considered as a major health problem, and the infections caused by MDR pathogens affect the effectiveness of antimicrobial drugs and are associated with a high death rate. Resistance among a variety of drugs has been increased all around the globe due to the extensive use of antibiotics (Pfaller et al., 1997). Initially, these MDR species were restricted to the hospital environment, but now they can be found everywhere and became a prevalent cause of community-acquired infections (Lipsitch, 2001; Lipsitch and Samore, 2002). Nowadays, it has becomes difficult to treat infections due not only to the antimicrobial resistance but also the suppressed immune function, deprived drug bioavailability, or increased rate of drug metabolism. Persistence of microbes after standard treatments points out different types of anti microbial drug resistance which is an expanding problem in medical world. MDR can be classified as primary or secondary resistance.

\subsection{Primary resistance}

It occurs when the organism has never encountered the drug of interest in a particular host.

\subsection{Secondary resistance}

Also known as "acquired resistance," which only arises in an organism after an exposure to the drug (Loeffler, 2003; Khalilzadeh, 2006). Secondary resistant is further of two types: Intrinsic and acquired resistance.

\subsubsection{Intrinsic resistance}

The inherent property of the microbes to resist the effect of a drug is classified as intrinsic resistance (Cox and Wright, 2013). Intrinsic resistance can also be termed as 'insensitivity' because of the insusceptible nature of the pathogen against particular drugs (Table 1). Intrinsic resistance is associated with the naturally occurring genes like AmpC or $\beta$-lactamase, which are found on the host chromosomes. Different mechanisms involved in the development of intrinsic resistance include modification of target sites, modification of antimicrobial agents, and presence of efflux pumps, low drug delivery, chemically induced adaptive changes, and stress response.

Table 1. Common bacteria with intrinsic resistance

\begin{tabular}{|l|l|}
\hline Name of organisms & Intrinsic resistance \\
\hline E. coli & Macrolides, tetracycline, penicillin, $\beta$-lactams \\
\hline Bacteroides & Quinolones, penicillin, aminoglycosides, many $\beta$-lactams \\
\hline Acinetobacter species & Glycopeptides, trimethoprim, chloramphenicol, ampicillin \\
\hline P. aeruginosa & $\begin{array}{l}\text { Cephalosporins, tetracyclines, trimethoprim-sulfamethoxazole, chloramphenicols, } \\
\text { sulfonamides, ampicillin }\end{array}$ \\
\hline Klebsiella spp. & Ampicillin, amoxicillin-clavulanate, ampicillin-sulbactam combination \\
\hline Enterococci & Cephalosporins, trimethoprim, aminoglycosides, lincosamides, colistin \\
\hline Serratia marcescens & Macrolides, ampicillin-sulbactam combination, ampicillin-clavulanate combination \\
\hline
\end{tabular}

\subsubsection{Acquired resistance}

In acquired resistance, genes targeted by antibiotics undergo mutations, and transfer the resistance determinants present on plasmids, transposons, and other transposable elements. The change in the genetic constitution of pathogens occurs due to gene transfer, gene alteration in stress regulating genes which in turn results in a change in protein expression and gene amplification methods (Flintoff, 1989). In general, the transfer of genes takes place by three processes involving: conjugation, transformation and transduction (Levy and Marshall, 2004). The most common method for the transmission of drug resistance requires conjugation, which is promoted by plasmids. During conjugation, "Pilus" is formed by plasmid between two adjacent bacteria to facilitate the transfer of genetic material. Transformation involves the uptake of exogenous DNA from surrounding or incorporation of DNA from the dying organism into the other recipient organism genetic cassette (Levy and Marshall, 2004). Transduction is carried out by vectors (especially bacteriophages) that carry drug resistance genes and introduce them into the bacterial host. In a single bacterium, multiple plasmids carrying genes for resistance are present that have the ability to replicate independently to host chromosomes. These plasmids are differentiated by their origin of replication. Transposons are the transposable elements also termed as "jumping genes" present on a plasmid or can also integrate into other transposons or host chromosomes (Frost, 2005).

\section{Multidrugresistant pathogens}

Pathogens resistant to more than one antibiotic are termed multidrug-resistant pathogens. They are considered as one of the most important public health problems and major challenges to global drug discovery programmes (Vivas, 2019). Initially, MDR pathogens were restricted to hospital environments, but now they 
can be found everywhere. In community acquired infections, MDR organisms are increasingly found. MDR infections have an impact on the effectiveness of antimicrobial agents and are associated with a high mortality rate. Such infections represent prolonged illness, an economic burden for the healthcare system and the immense risk of death (CDC, 2021). Due to resistance against many antibiotics, infections caused by MDR pathogens are mainly untreatable. MDR is a natural phenomenon; excessive use of antibiotics, poor sanitary conditions, inappropriate practices of infection prevention and control also lead to the spread of MDR. As per a report from the CDC (Centers for Disease Control and Prevention), more than 2 million infected and about 23,000 people die due to antibiotic resistant bacteria every year in the USA. Pathogens responsible for such an increase in the infection rates include methicillin-resistant $S$. aureus (MRSA), Vancomycin-resistant E. coli and fluoroquinolone-resistant $P$. aeruginosa (Solomon and Oliver, 2014). Due to the huge increase in multidrug-resistant pathogens, there is a decrease in antimicrobial agents which are used to treat infections caused by these pathogens (Cerceo, 2016). It was estimated that by 2050, if no new drugs are developed, there will be no antibiotics available to treat the infections effectively (Rolain, 2016). This leads to arise the need to search alternative methods for controlling antibiotic resistant pathogens. Almost all infectious agents like bacteria, fungi, viruses, and parasites show resistance toward multiple drugs and are able to resist attack by antimicrobial drugs, which results in ineffective treatment and spread of infections.

\section{Mechanisms of MDR}

Resistance is the insensitivity of a microbe to an antimicrobial drug when compared with other isolates of the same species. However, several new antimicrobial agents have been introduced commercially; this resistance development among infectious microorganisms is increasing especially in patients under prolonged drug exposure (Loeffler and Stevens, 2013). Antimicrobial agents generally act on the microbes either by prohibiting a metabolic pathway like synthesis of nucleotide which in turn leads to the inhibition of DNA/RNA synthesis and further protein synthesis and disruption of the cell membrane or by competing with the substrate of any enzyme involved in cell wall synthesis (Chethana et al., 2013). Microorganisms have evolved many mechanisms to overcome the effectiveness of antimicrobial agents, therefore, they can survive under the exposure of antimicrobial agents.

Cell wall of bacteria and fungi plays an important role in their survival and most of the antimicrobial agents inhibit the cell wall synthesis by binding with the peptidoglycan layer in bacteria or affecting ergosterol synthesis (He et al., 2013). This blocks the cell growth and division in bacteria and fungi. Microorganisms undergo certain chromosomal mutations (Alekshun et al., 2007) or exchange of plasmid DNA through conjugation or transformation (WHO, 2014), which can cause changes in the cell membrane composition, resulting in decreased, permeability and uptake of drugs into the cell (Singh, 2013; Loeffler et al., 2003; Chethanaet al., 2013; Tenover, 2006). Altered membrane composition in microorganisms also lead to lack of active target sites for the drugs to bind (He et al., 2013). Mutations in the genes that encode for the target, cause modifications at the molecular level and retain cellular function by reducing susceptibility to antimicrobial agents (Singh, 2013; Chethana et al., 2013).
The MDR among microorganisms can also be by the over expression of drug target enzymes which lead to target bypass due to modification in certain metabolic pathways e.g., azoles and allylamines in fungi (He et al., 2013), or causes the production of alternate target molecules and interference in some protein synthesis. This can affect the entry of drugs to the target sites. Enzymatic degradation of drugs occurs by hydrolysis of ester or amide bonds (such as resistanceto $\beta$-lactams due to $\beta$-lactamases) and hydroxylation of drug has also become increasingly apparent as causes of MDR (Singh, 2013; Chethana et al., 2013; Alekshun and Levy, 2007). The resistant strains of clinical isolates also developed the ability to oxidize or reduce the drugs to prevent their interaction with the respective targets (Chethana et al., 2013). MDR in parasites is also a global public health threat.These parasites also undergo certain point mutations resulting in altered drug targets, alter calcium homeostasis in endoplasmic reticulum and expel drugs out of the cells (McFadden et al., 2000; Bloland, 2001).

Efflux pumps remain the predominant mechanism of MDR. The over expression of genes encoding for ATP-binding cassette transporter membrane proteins (e.g., P-glycoprotein), also known as the multidrug efflux pumps are responsible for the export or expulsion of drugs out of the cell (Nikaido, 2009; Alekshun and Levy, 2007; Li, 2009) and usually generates MDR and continues cellular functions without any interference. Over expression of Pglycoprotein, in Entamoeba spp. and Leishmania spp. membrane or multidrug-resistant proteins (MRP), affects the fluidity and permeability, leading to an ATP-dependent efflux of the antimicrobials and decreasing their intracellular concentration (Bansal et al., 2006; Orozco et al., 2002; Ouellette et al., 2001). Superbugs are bacteria-resistance to one or more antibiotics, and they make difficult to treat or cure infections that once were easily treated. The antibiotic has lost its ability to control or kill bacterial growth because they have developed genes for resistance and that gene protects them (Alain, 2017). Various mechanisms involved in MDR include extrinsic as well as intrinsic mechanisms (Figure 1).

6.1 Extrinsic mechanisms of MDR

\subsubsection{Modification/absence of target site}

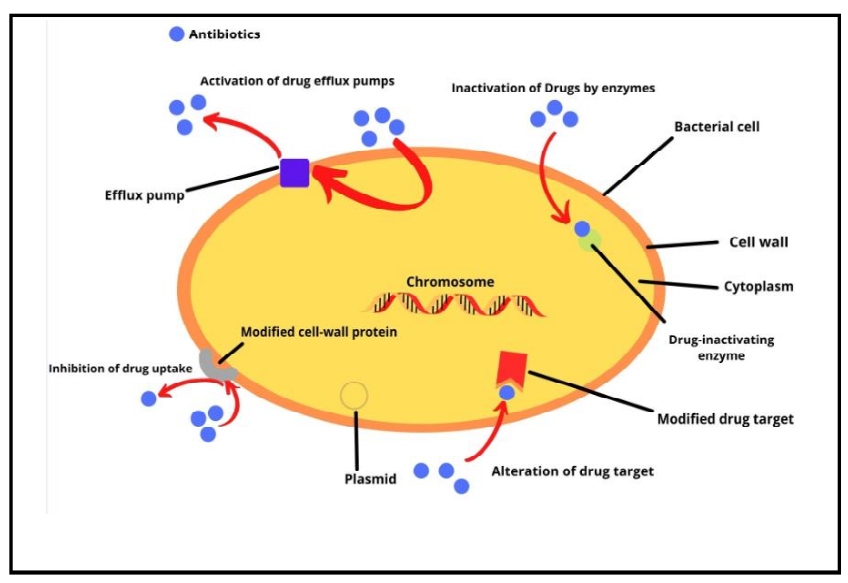

Figure 1: Various mechanisms of multidrug-resistance among bacteria (Bbosa et al., 2014). 
The uptake of antimicrobial drugs by microorganisms is essential for effective action of the drug against the specific target. In the outer membrane of Gram-negative bacteria, pore proteins called porins are present, which mediates the transfer of drugs to cross outer membranes of bacterial cells. In order to protect themselves from the action of drugs, some bacteria can modify the cell wall or membrane, as in the case of Gram-negative bacteria (Ray et al., 2017). These bacteria modify the frequency and size of porin present on the outer membrane to decrease the uptake of certain bacteria, such as aminoglycosides. Similarly, modification in the penicillinbinding protein site results in resistance against many $\beta$-lactam antibiotics (Malouin and Bryan, 1986).

\subsubsection{Limiting drug uptake and biofilm formation}

The most common mechanism of intrinsic resistance is to reduce the permeability of the outer membrane within Gram-negative bacteria. The barrier to different types of drugs is provided by the lipid polysaccharide layer at the outer membrane, which confers innate resistance to various groups of antimicrobial agents (Blair $e t$ al., 2014). The outer membrane of Mycobacterium has high lipid content, due to which drugs such as rifampicin, fluoroquinolones (hydrophobic drugs) have easier access to cells, whereas hydrophilic drugs have limited access ( $\mathrm{Pa}, 2002$; Kumar and Schweizer, 2005). The formation of biofilm by the bacterial community is the most common phenomenon of bacterial colonization. Biofilms are the clusters of bacteria that are firmly attached to the surface by means of tendrils, filaments and provide protection to bacteria from the attack by the host immune system, as well as from the antimicrobial drugs (Kanwar et al., 2019).

These biofilms are surrounded by the thick, sticky coating of polysaccharides, proteins and DNA from resident bacteria that form the barrier, thus preventing antimicrobial drugs from reaching the bacteria. Therefore, to be effective, a much higher concentration of drugs is required. The complex three-dimensional structure of biofilm contains transport proteins, which helps in the uptake of nutrients, disposal of waste material, thereby helping in the pumping of drugs out of cells. Moreover, less oxygen and fewer nutrients are available for bacterial cells deep within the biofilm; therefore, these cells have slow cell division and metabolism. Hence, these are less susceptible to the action of antimicrobial drugs, which tends to target fast-growing and dividing bacterial cells. Bacteria that are capable of forming biofilm include Salmonella sp. on environmental surfaces, Neisseria sp. as dental plaque on teeth, Staphylococcus intermediates on orthopaedic implants and pacemakers (Kanwar et al., 2018).

\subsubsection{Inactivation of antimicrobial drugs via modification and degradation}

Sometimes, microbes modify or destroy the active component of antimicrobial drugs in order to protect themselves from the harmful effect of a drug or to gain resistance against that particular drug. Many Gram-negative and Gram-positive bacteria possess this ability against various drugs such as chloramphenicol or aminoglycosides. The modification or deactivation of the $\beta$-lactam ring in case of penicillin and cephalosporins to produce inactive penicilloic acid, which is not able to bind to PBPs and; therefore, bacteria are able to maintain cell wall synthesis (Waxman and Strominger, 1983).

\subsubsection{High detoxication capacity}

In order to escape the attack of predators and other competitors, many bacteria produce various toxic compounds. Such bacteria also possess the ability to escape the harmful effects of those toxic chemicals secreted by them (Ray et al., 2017). These bacteria inactivate antibiotic products like streptomycin and neomycin secreted by them to develop resistance against drugs with the help of phosphotransferases and acetyltransferases. Moreover, in the case of higher organisms, protein expression that is associated with protection against various chemicals is highly tissue-specific. The mammalian lungs have developed the large number of resistance mechanisms, including glucose-6-phosphate, dehydrogenase, $\beta$ tocopherol, glutathione, catalase, superoxide dismutase, mainly due to their ability to resist the damage caused by oxygen-induced free radicals. Similarly, due to direct exposure to the environment, the bronchiolar epithelium contains a large number of detoxication enzymes.

\subsubsection{Cell cycle effects}

Rate of cell division in case of mammalian cells (solely tumor cells), is mainly responsible for the intrinsic drug resistance. The main dose-limiting factor is rapidly dividing normal cells in case of cancer chemotherapy and mostly, the antineoplastic drugs which are beneficial in treatment of cancerous disease are effective against quickly dividing malignant cells. Therefore, tumors in G0 resting state are slow growing and many anticancer drugs are not very effective on these slow growing cells.

\subsubsection{Species specific structure of target}

The species specificity has been observed in some cases due to the lack of affinity of drug to its binding site. Under a single genus of bacteria, by presenting various structural motifs for the same target, different species alter drug binding sites, therefore, developing resistance against these drugs (Alekshun and Levy, 2007). The crystal structure of large ribosomal subunits in S.aureus shows specific motifs and binding modes for different antibiotics of same functions and helps the bacterium to develop resistance against many antibiotics.

\subsection{Extrinsic mechanisms of MDR}

\subsubsection{Resistance through chromosomal mutation}

\section{(a) Fluoroquinolones}

Many bacteria develop fluoroquinolone resistance with the help of mutations, which inturn makes the target protein less susceptible to agent. However, fluoroquinolones resistance is mainly associated with the mutations within the target sites and drugs, such as DNA topoisomerase and DNA gyrase (Hooper, 2000; Drlica and Malik, 2003). These drug targets, when altered due to mutations, develop resistance against fluoroquinolones. These components are involved in the various ATP-dependent functions during the process of DNA replication. These multi-subunit complexes consist of two subunits, GyrA and GyrB for DNA gyrase and ParC/Grl/A and ParE/GrlB for topoisomerase IV. Fluoroquinolones, mainly target subunit GyrA and ParC/GryA to perform DNA-binding functions, whereas subunit ParE/GrlB and GyrB help in ATP binding and breakdown are targeted by coumarin antibiotics. Mutations which are involved in fluoroquinolones occur first on DNA gyrase of Gram-negative 
bacteria, whereas, in Gram-positive, mutations initially arise in topoisomerase IV. These mutations are mainly found in the quinolone-resistance-determining-region (QRDR) of GyrA and ParC/ GrlA, and therefore, pathogens that are resistant to fluoroquinolones bear many QRDR mutations as well as other fluoroquinolone resistance mechanism such as drug efflux.

\section{(b) Rifamycin}

Rifamycin is the bactericidal drugs, which either alone or in combination with other drugs like isoniazid, streptomycin, pyrazinamide is the primary choice of therapeutic drug against $M$. tuberculosis infections. Rifamycin interacts with the RpoB, thereby, arresting the transcription. However, point mutations at the rifamycin binding site of RpoB at the frequency of about $1 \times 10^{-8}$ prevent the binding affinity of the drug at the RNA polymerase subunit, thereby providing resistance against the drug (Mariam et al., 2004). M. tuberculosis is resistant to these drugs and prevents efficient therapy among patients in different regions of the world (Sharma and Mohan, 2006)

\section{(c) Sulfonamide and trimethoprim antibiotics}

Sulfonamides were the first antimicrobials developed for large scale introduction into clinical practices, which targets dihydropteroate synthase. Mutation results in the alteration of dihydropteroate synthase, which in turn decreases the affinity of the enzyme for sulfonamides in E. coli and S. pneumoniae (Sköld, 2001). Trimethoprim causes inhibition of dihydrofolate reductase enzyme. Mutations in the gene specifying dihydrofolate reductase results in high level production of drug resistant enzymes with reduced drug affinity and therefore, provide resistance among $E$. coli and $H$. influenza against trimethoprim (Sköld, 2001).

\section{(d) Tetracycline, aminoglycoside and MLS antibiotics}

Antibiotic resistance is also attained by point mutations at the ribosomes, which inhibit the protein translation. Components present in the tetracycline, aminoglycoside and MLS antibiotics target the ribosomes, as a result of which protein translation is inhibited. Tetracycline and aminoglycoside bind with 16SrRNA (rrs) whereas MLS antibiotics interact specifically with 23SrRNA (rrl). Resistance cannot be attained without mutation in all or majority of other operons therefore, resistance among tetracycline and MLS antibiotics is achieved by point mutation at 16SrRNA and 23SrRNA operons respectively (Ross, 1998).

\section{(e) Oxazolidinones}

Linezolid acts as an inhibitor of protein synthesis and was approved for treating the infections caused by methicillin-resistant $S$. aureus as well as vancomycin-resistant Enterococci. It is useful for treating both nosocomial and community-acquired infections because it is available in both intravenous as well as oral formulation. Point mutations in rrl results in linezolid resistance in $S$. aureus and $E$. faecalis. Moreover, linezolid resistance due to point mutation at rrl has also been documented in strains of S. epidermidis, E. faecium, E. faecalis. S. aureus and Streptococcus oralis (Eliopoulos et al., 2004). The resistance in S.aureus increases with the increase of mutations in multiple rrl operons (Wilson, 2003).

\subsubsection{Genomic duplication}

Genome duplication or gene amplification is genomic doubling which results in the overexpression of drug targets and is the most common mechanism of drug resistance in eukaryotic cells (Albertson, 2006). In $E$. coli genomic doubling at acrAB locus in the presence of tetracycline results in the overexpression of AcrAB drug efflux pump, thereby, producing multidrug-resistance phenotype (Nikaido and Zgurskaya, 2001). Such type of amplification was observed in $S$. aureus, with respect to methicillin resistance (Matthews and Stewart, 1998). This type of mechanism is unstable because the microbes revert back to their normal phenotype in the absence of drug (Nicoloff et al., 2007).

\subsubsection{Enzymatic drug modification or inactivation}

Inactivation of drugs by means of enzymes is a common resistance mechanism, in which resistance genes encodes for enzymes that have ability to chemically modify the antimicrobial drugs, therefore, inactivating them through different processes like hydrolysis, phosphorylation, adenylation, acetylation. This mechanism is very common for the antibiotics of natural origin such as, aminoglycosides (amikacin, kanamycin), which are inactivated by enzymatic phosphorylation with the help of enzyme aminoglycoside phosphoryl transferase (APH), or by acetylation involving aminoglycoside acetyltransferase (ACC), or by adenylation catalyzed by aminoglycoside adenyltransferase. $\beta$-lactam antibiotics such as penicillin, cephalosporins, and carbapenems are inactivated by the process of hydrolysis carried out by $\beta$-lactamases. Mechanism of enzymatic drug modification includes two types of enzymes; enzymes that are responsible for degradation of antibiotics/drugs such as $\beta$-lactamases, and other enzymes that result in chemical transformation including macrolide and aminoglycoside modifying enzymes (Kumar et al., 2013; Blair, 2015).

\section{(a) $\beta$-lactamases}

$\beta$-lactamases are the enzymes that catalyze the enzymatic hydrolysis of the $\beta$-lactam bonds within the $\beta$-lactam ring of the drug molecule, causing the ring to open. The open ring drugs are not able to bind with target proteins as a result of which, the drug molecule loses its antimicrobial activity. This is the most common mechanism of $\beta$-lactam resistance, mediated by $\beta$-lactamases. Most of these resistances are associated with resistance genes present on plasmid or transposons, which encodes for $\beta$-lactamases and provide intrinsic resistance. On the basis of structure and functions, $\beta$-lactamases have been divided into two categories; one with serine at the active catalytic site and the other require metal ion cofactor (such as zinc-dependent metalloenzymes) (Jacoby and MunozPrice, 2005). The $\beta$-lactamases with serine active site are classified into class A,C and D enzyme groups, whereas, $\beta$-lactamases with zinc-dependent metalloenzyme are classified in class B. Class A,C and $D$ enzymes function as extended-spectrum- $\beta$-lactamases, whereas class B metalloenzymes function as carbapenemases that catalyze the hydrolysis of carbapenems. As class B enzymes are zinc-dependent, they are inhibited by EDTA. An inducible or plasmidborne enzyme, $A m p C$ is proteotypic class $C$ enzyme, found in many strains of Enterobacteriaceae and P. aeruginosa, can be easily transfer to E. coli, Klebsiella sp. and Salmonella sp.(Jacoby, 2009). 


\section{(b) Aminoglycosides}

Large number of enzymes that possess the ability to modify the aminoglycosides are present on mobile genetic units and integrons and are widely spread in clinically important organism (Davies and Wright, 1997). Resistance among aminoglycosides can be achieved by aminoglycoside modifying enzymes such as acetyltransferases, phosphotransferases and adenylates that reduce the net positive charges on these polycationic antibiotics. Aminoglycosides such as tobramycin, gentamicin, and amikacin are modified by acetyltransferases, whereas adenylates results in the modification of tobramycin activity and susceptibility of amikacin is affected by phosphotransferases. On integrons and transposable genetic elements, these modifying enzymes are further associated with other resistance determinants. In $P$. aeruginosa, three acetyltransferase genes were found on class 1 integrons, that also confer resistance to carbapenems and sulfonamides (Poirel, 2001).

\section{(c) Modulated drug targets}

Alteration, substitution or modification of the targets of antimicrobial drugs helps in developing resistance against them. In the 1940s, the first penicillin and methicillin resistant $\beta$-lactamase producing strain of S.aureus was identified. The gene encodes for $\beta$-lactamase helps in altering the penicillin binding protein (PBPs), thereby confers resistance against methicillin in Staphylococcus (Fuda et al., 2005) as well as Streptococcus (Jacobs, 1999). The altered penicillin binding proteins (PBP2a) is encoded by the mecA gene present on the mobile genetic element called "Staphylococcal cassette chromosome" (SCCmec) of the methicillin resistant $S$. aureus (Wielders, 2001). The mobile genetic element contains regulatory loci (mecR1-mecI) and enzymes responsible for sitespecific recombination.

In $S$. aureus, processes of cell wall synthesis require large number of PBPs. PBP2 enzyme is bifunctional and plays a double role in $S$. aureus, involving transpeptidase and transglycosylase activities, which switch their role on the basis of exposure to drug (Brown and Reynolds, 1980). PBP2 functions as transglycosylase while PBP2a functions as transpeptidase, thereby providing resistance to all $\beta$-lactam antibiotics. The plasmid borne qnr determinants which affect the sensitivity of fluoroquinolones have been found mainly in Gram-negative sp. of E. coli, Shigella, Salmonella, and provide the mechanism of decreased fluoroquinolone susceptibility (Piekarska, 2012). Qnr belongs to the pentapeptide repeat family of proteins, which regulates the resistance among fluoroquinolone by protecting DNA gyrase and topoisomerase IV, respectively, from the action of fluoroquinolones (Tran and Jacoby, 2002).

Moreover, another resistance mechanism of fluoroquinolone is MfpA, found in Mycobacterium, belongs to pentapeptide protein family, contain single type II topoisomerase with ability to mimic the structure of $\beta$-form DNA. Therefore, it acts as inhibitor of DNA gyrase of $M$. tuberculosis. Interaction of MfpA with Qnr has inhibitory effect on ciprofloxacin (Montero, 2001) and the organisms (bearing Qnr or MfpA), which can survive in the presence of low fluoroquinolone concentration favour the selection of fluoroquinolone resistance. Another major example of drug resistance is due to modification of drug targets of glycopeptides, found mainly in the Gram-positive spherical bacteria (Courvalin, 2006). These glycopeptides exert bactericidal activity by interacting with the peptidoglycan precursors. In Enterococci, acquired glycopeptide resistance is associated with VanA, VanB, VanD, VanE and VanC phenotypes, where VanA and VanD confers resistance against both vancomycin and teicoplanin, whereas, VanC confers intrinsic resistance.

Multiple proteins specified in the gene clusters contribute the resistance phenotype and result in the production of modified peptidoglycan. The activity of many enzymes specified by gene clusters is involved in developing glycopeptide resistance. Recemases and dehydrogenases produce serine and lactate from pyruvate and result in modification of peptidoglycan structure. These two component units regulate the mechanism of cellular biosynthesis. If an intact D-Ala is available, glycopeptides having low affinity for D-Ala-D-serine and D-Ala-D-lac substrates can still bind and inhibit cellular biosynthesis. To overcome this, dipeptidase and carboxypeptidase perform their functions of cleaving and removing terminal D-alanine. Dipeptidase cleaves Cterminal D-Ala-D-Ala whereas carboxypeptidase results in removal of terminal D-Ala. The VanA gene cluster, which is responsible for vancomycin resistance in Enterococcus has transferred its resistance determinants in methicillin resistant $S$. aureus, where these determinants reside on plasmid encodes Tn1546 transposon (Weigel, 2003). It was assumed that the plasmids from E. faecalis function as vehicles for the transfer of VanA into S. aureus.

\section{(d) Efflux mechanism}

The envelopes of Gram-negative bacteria affect the susceptibility of the drugs by inhibiting its penetration ( $\mathrm{Li}$ and Nikaido, 2004). Because of the efflux mechanism, which ejects the drugs out of the cell, most of the antimicrobial drugs penetrate the Gram-negative organisms, but they are not able to reach intracellular targets (Levy, 1992). In this mechanism, five protein transporter families have been involved which include; ATP-binding cassette (ABC) transporters, major facilitator (MF) protein groups, small multidrug resistance (SMR) units, resistance-nodulation-cell-division (RND) family, and multidrug and toxic compound extrusion (MATE) protein super family, (Poole, 2005) (Figure 2).

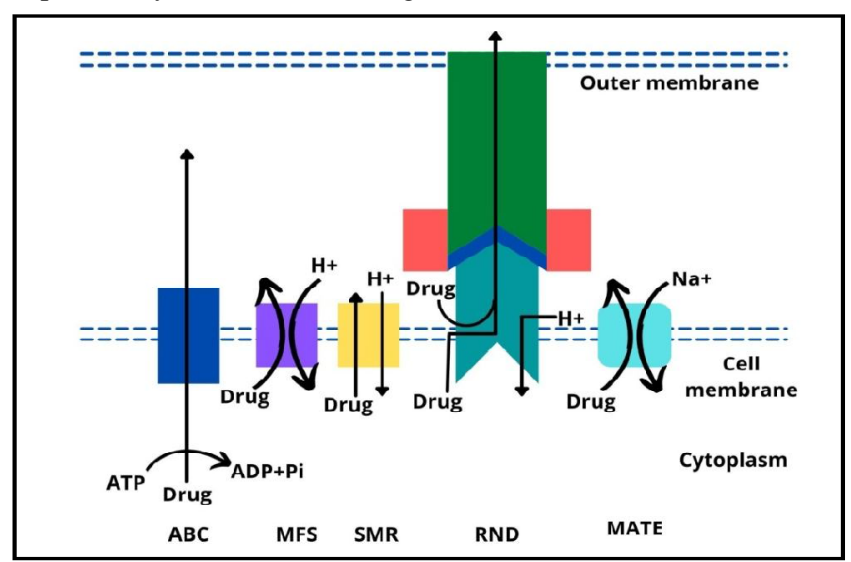

Figure 2: General structure of main efflux pump families.

Most of these efflux pumps transport drugs across cytoplasmic membranes (single-compound pumps), whereas, the RND family are multi-component pumps, which pumps out substrates across the entire cell envelope. These pumps function in association with periplasmic membrane fusion proteins (MFP) and outer membrane 
protein (OMP-porin) (Kumar and Schweizer, 2005; Poole, 2007; Blair et al., 2014). For efflux mechanism, ATP hydrolysis is performed by $\mathrm{ABC}$ group of primary transporters, while other transporter groups employ proton-motive gradient force to eject the drugs out of cells (Kobayashi et al., 2001).

\section{Approaches to combat the emergence of antimicrobial resistance or MDR}

It has been suggested to use the appropriate antimicrobial agents (no antibiotics for viral infections) to limit the development of antimicrobial resistance. Identify the causative organism whenever possible, select an antimicrobial which target the specific organism rather than relying on broad spectrum antimicrobial. Although, overuse of antibiotics is mostly responsible for antibiotic resistant in bacteria, several studies have revealed that treatment indications, agent choice, and antibiotic therapy duration are inappropriate in $30 \%-50 \%$ of the cases (Ventola, 2015; Lushniak, 2014). World population are now facing infections with a limited number of therapeutic options and alternative treatment must be developed. These options are either based on specific targets on the MDR bacteria or designed to improve the host response to the infectious injury (Anne-Sophie and Benoit, 2017).

\subsection{Problems associated with MDR}

The major problems associated with the MDR are, high mortality rates and high medical costs of treatment and these have significant impact on the effectiveness of antimicrobial agents (Figure 3). MDR cause problems in disease control by enhancing the possibility of spreading of resistant pathogens, and thus decline the efficacy of treatment and results in prolonged time of infection in patient. The cost of treatment of disease is increased due to MDR as the pathogens become more resistant to commercially available drugs, which has triggered the use of more expensive therapies. The resistance profile of bacterial and fungal as well as the quality of public hygiene also has a considerable impact on the effectiveness of antimicrobial agents especially in developing countries (WHO, 2014; Fishbain, 2010).

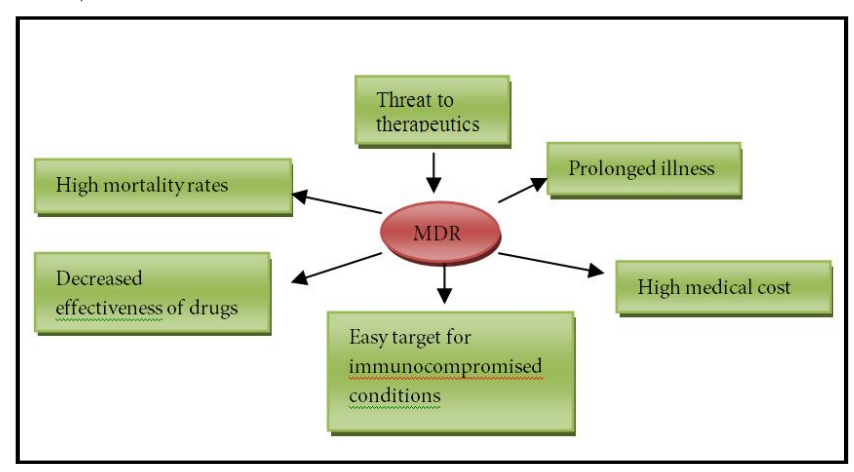

Figure 3: Problems associated with MDR (Tanwar et al., 2014).

Plasmid is an extra chromosomal DNA molecule that carries the resistance property against drugs in bacteria. R-plasmids from resistant strains of pathogenic bacteria may transfer to sensitive bacteria that would show the same drug resistance as the donor strain (Datta, 1972). Plasmids can also be eliminated from bacteria by using curing agents. Different use of chemical agents such as intercalating dyes (acridine orange, ethidium bromide), treatment with crystal violet, SDS, thymidine starvation and exposure to UV radiation, exposing the host strain to elevated temperatures helps in plasmid curing (Clowers, 1972).

\subsection{Plasmid curing}

Plasmid curing is the elimination of plasmid DNA from bacterial isolates in order to determine the relationship of multidrug resistance with plasmid DNA (Raj, 2012). This is an attractive approach to combat antimicrobial resistance, the plasmid curing agents have the potential to remove antimicrobial resistant genes from a population while leaving the bacterial community intact. This means, the gastrointestinal microbiome of a chicken treated with a plasmid curing agent might remain largely unchanged, but potentially pathogenic bacteria which may unfortunately be transmitted into the food chain would be susceptible to antibiotics. Alternatively, a plasmid curing agent could be given to a patient prior to surgery, to reduce the resistant hospital acquired infection. Plasmid curing agents could also be taken by international travelers to reduce the global spread of antimicrobial resistance, but the plasmid curing agents should be safer for the human beings; they should not show any impact on the microbiome. Furthermore, removing drug-resistance plasmids is a strategy for all sectors to reduce the overall burden of antimicrobial resistance. For example, plasmid curing agents could be used to remove antimicrobial resistant genes from bacteria in sewage before release into the environment. Human and animal waste is often recycled and used to fertilize agricultural land; this can contain high concentrations and varieties of antimicrobial resistant genes which can be passed on to people (Meek et al., 2015; Rahube et al. 2016). Abundance of antimicrobial resistant genes have been detected in plasmid metagenome libraries constructed from the activated sludge and digested sludge from two waste water treatment plants, demonstrating that these were important reservoirs of antimicrobial resistant genes. Treatment of sewage with plasmid curing agents will help in reducing the antimicrobial resistant genes (Li and Zhang 2015).

\subsection{Plasmid curing compounds}

In bacteria, resistance occurs with the accumulation of genes coding for resistance to specific agents on the plasmids, most commonly on R-plasmids (Schelz et al., 2006). Plasmids are independent, circular, extrachromosomal DNA elements capable of replicating independently of the host cell. Plasmid encodes different types of properties, including resistance to antimicrobial drugs, heavy metals and degradation of hydrocarbons. Many compounds have shown some plasmid curing activity which include detergents, biocides, DNA intercalating agents, antibiotics (aminocoumarins, quinolones, rifampicin), ascorbic acid, plant-derived compounds and lactic acid bacteria. The effectiveness of these compounds varies and depends on bacterial strain, plasmid and growth conditions. Plasmid curing compounds act through different mechanisms, in many cases, they disrupt plasmid replication by integrating into the DNA (intercalating agents and chlorpromazine), cause breaks in DNA (ascorbic acid) or influence plasmid supercoiling (amino coumarins and quinolones). Each of these can result in reduced plasmid prevalence within the population over time (Michelle et al., 2018). Unfortunately, at the moment no such treatment options are in use. In fact, there are very few curing mechanisms that have been tested in vivo, even in experimental models. Therefore, research in this area is urgently needed. It was shown that $24 \%$ of non-antibacterial drugs impact 
the growth of members of the human microbiome (Maier et al., 2018). LAB extracts also showed antibacterial and anti-plasmid effect against multidrug resistant bacterial strains and are also safer for human beings (Nehal et al., 2015).

However, no single antimicrobial agent has the ability to cure all the plasmids from different hosts. Some of these curing agents such as acridine orange, ethidium bromide, and SDS are very toxic and mutagenic in nature; therefore, not suitable for therapeutic applications. Thus, the development of new non-toxic agents with high efficiency and safety are necessary to reduce the development of MDR. On the basis of various studies, LABs come under the category of generally recognized as safe (GRAS). Moreover, extracellular and intracellular fractions purified from LAB extract have various antimicrobial and anti-plasmid activities against MDR bacterial strains.

\subsubsection{Detergents}

Detergents, bile and sodium dodecyl sulfate (SDS) an anionic surface-activating agent, are powerful agent for curing of plasmids (Tomoeda et al., 1968; Inuzuka et al., 1969). SDS known to eliminate certain plasmids determining constitutive synthesis of $\mathrm{F}$ pili, had no effect on cultures with wild-type (repressed) R factors (Vyvyan et al.,1972). SDS was effective in eliminating F-lac and the R factor RIoodrdr (Tomoeda et al., 1969). Both these plasmids produce Flike pili constitutively (Nishimura et al., 1967). SDS also had other effects on bacteria, which include changes in the peptidoglycan layer, bacterial cell size, septation and loss of outer membrane components (Rosas et al.,1983).

\subsubsection{DNA intercalating agents}

Intercalating agents such as acridine orange and ethidium bromide have played an important role in curing bacterial plasmids. The modes of action of intercalating agents are through preferential inhibition of plasmid replication (Vengadesh , 2015). Acriflavine cured some resistance plasmids from Salmonella oranienburg, $S$. Panama and E. coli $\mathrm{K} 12$ in vitro and in amurine in vivo model (Bouanchaud and Chabbert 1971). Acriflavine, acridine orange and ethidium bromide cured resistance to antimicrobials from both donor and transconjugants $B$. fragilis and B. thetaiotaomicron (Rotimiet al., 1981).

\subsubsection{Antibiotics}

The plasmid-mediated resistance to the compound emerges and subsequently spreads after the introduction of a new antibiotic into medical practice. Bacterial resistance of this type is likely to precede the clinical use of the new molecule, but use of the antibiotic favors selection, dissemination, and hence detection of resistance. The availability of the drug is a prerequisite for screening and finding, by medical microbiologists, of the new resistance phenotype. As usual, there are a few exceptions to the rule; nitrofurans, novobiocin, polypeptides, quinolones, and rifampin have no known plasmidmediated resistance (San,1990). It is noteworthy that novobiocin (coumermycin), which also inhibits DNA gyrase, belongs to this group. There has been a single report of plasmid-mediated resistance to nalidixic acid in bacteria (Munshi, 1987).

\subsubsection{Ascorbic acid}

Ascorbic acid (vitamin C) is a readily available compound which is a non-hazardous curing agent and safe to handle and have demonstrated the physical loss of a plasmid from a strain of Pediococcus acidilactici CFR K7 which was previously shown to be a pediocin producer (Ramesh et al., 2000). The effect of ascorbic acid was also noticed in curing of Serratia marcescnes plasmid. In S. aureus, $1 \mathrm{mM}$ ascorbic acid resulted in loss of penicillin and aminoglycoside resistance encoding plasmids (Amábile Cuevas,1988; Amábile-Cuevas et al., 1991). Two plasmids, pI258 (penicillin resistance) and pT181 (tetracycline resistance), were not cured by ascorbic acid. However, there was a significant decrease in the MIC of tetracycline, which might be due to reduction in plasmid copy number (Amabile-Cuevas et al.,1991).

\section{Plasmid curing by LAB}

Lactic acid bacteria (LAB) are a group of Gram-positive, nonsporulating, anaerobic or facultative aerobic cocci or rod shape bacteria (Hayek and Ibrahim, 2013). They play an important role in food production and health maintenance (Emiliano et al., 2014). They are of particular interest to the food industry (Nettles and Barefoot, 1993), since these bacteria have generally been regarded as safe (GRAS status). Their growth lowers, the carbohydrate content of the food they ferment as well as the $\mathrm{pH}$ due to lactic acid production. LAB secretes antimicrobial compounds of low molecular weight, cationic proteins, and bactericidal to other Grampositive bacteria (Klaenhammer, 1988). These antimicrobial compounds have long been used in fermentations to preserve the nutritive qualities of various foods. This bioactive compound may be proteinaceous bacteriocin (Tagg et al., 1976). Most of these LAB live in harmless and beneficial association with humans and generally found on decaying plant materials, milk and milk products. In human and animal, they are part of normal flora and natural inhabitants of intestinal tract, oral cavity and the vagina, where they play beneficial roles (Ayivi et al., 2020). Moreover, various members of the LAB are used commercially as a starter culture in the manufacture of dairy products such as yoghurt, butter-milk and hard and soft cheese (Hati et al., 2013). Fermentations of LAB results in the production of high quality nutritious and healthy food products which include meat, alcoholic beverages, vegetables, legumes, cereals and milk products. LAB also have many therapeutic properties which are beneficial for the improvement of human health (Carr $e t$ al., 2002).

\subsection{Bacteriocins produced by LAB}

Bacteria are developing resistant against antibiotics and this cause significant public health problem (Lipsitch, 2001; Lipsitch and Samore, 2002). MDR pathogens can transfer genes horizontally and this transfer of genes can take place by three ways, through plasmids, phages, or uptake of naked DNA (Thomas and Nielsen, 2005). Some microbial pathogens have acquired resistant against antibiotics due to their frequent uptake and bacteriocins have the advantage over conventional antibiotics. Bacteriocins are ribosomally synthesized peptides that have antibacterial activity towards closely related strains (De-Vuyst and Leroy, 2007; Cleveland et al., 2001). Bacteriocins can be produced by both Grampositive as well as Gram-negative bacteria, but bacteriocins produced by LAB are inherently tolerant to high thermal stress and 
are known for their activity over a wide $\mathrm{pH}$ range. Bacteriocin shows their antimicrobial mechanism by forming pores in the membrane of target bacteria, even at low concentrations. They can be easily degraded by proteolytic enzymes due to their proteinaceous nature and due to this, the fragments of bacteriocins do not live long in the human body or in the environment (U.S. Federal Register, 1988).

Bacteriocins obtained from $L$. fermentum were found to possess antimicrobial potential against methicillin resistant S.aureus (Nawaz et al., 2009). Bacteriocins produced by Lactobacilli strains isolated from yogurt was found to possess antimicrobial potential against cephalosporin resistant E. coli (Riaz et al., 2010). LAB produced antimicrobials might play a serious role during the in vivo interactions occurring in the human gastrointestinal tract and contribute to gut health (De-Vuyst and Leroy, 2007). This live biotherapeutic agent has been tried as alternative innovative approaches to antibiotics in treating gastrointestinal diseases (Daly and Davis, 1998; Soomro et al., 2002; Oyetayo et al., 2003).

\subsection{Reutericyclinproduced by LAB}

Reutericyclin is a low molecular weight antibiotic produced by LAB (Lactobacillus reuteri). It is hydrophobic in nature and structurally related to naturally occurring tetramic acids. It shows its antimicrobial effect on Gram-positive and Gramnegative bacteria, several fungi and yeasts (Ganzle and Vogel, 2003; Ganzle, 2004).

\subsection{Lactic acid produced by lactic acid bacteria}

The primary antimicrobial effect exert by LAB is the production of lactic acid (Mobolaji and Wuraola, 2011). Lactic acid shows antimicrobial activity by causing acidification of cytoplasm and failure of proton motive force. It increases the $\mathrm{pH}$ gradient within the cell and decreases the amount of energy required for cell growth and microbes failed to grow in the presence of lactic acid (Wee et al., 2006). It can inhibit the growth of both Grampositive and Gram-negative bacteria as well as yeast and mold (Rathanachahaikunsopon and Phumkhachorn, 2010). Different microorganisms vary in their sensitivity to lactic acid. The lactic acid was found to be inhibitory towards spore forming bacteria at $\mathrm{pH} 5.0$ whereas ineffective for yeast and mold (Yang, 2000).

\subsection{Hydrogen peroxide $\left(\mathrm{H}_{2} \mathrm{O}_{2}\right)$ produced by LAB}

Hydrogen peroxide produced by LAB can be used in food, pharmaceutical, dental products and textile industries (Abbas et al., 2010). $\mathrm{H}_{2} \mathrm{O}_{2}$ produced by LAB inhibit the growth of pathogenic bacteria at refrigeration temperature (Abriouel et al., 2004). $\mathrm{H}_{2} \mathrm{O}_{2}$ shows its antimicrobial effect by the oxidation of sulfhydryl groups, which cause denaturation of number of enzymes as well as peroxidation of membrane lipids to increase the membrane permeability. The $\mathrm{H}_{2} \mathrm{O}_{2}$ acts as precursor for the production of bactericidal free radicals such as superoxide and hydroxyl, which can damage DNA (Ammor et al., 2006).

\section{Conclusion}

Majority of pathogenic bacteria developed resistant against antibiotics and this resistance is mainly due to plasmids. Many plasmid curing agents have been used for the elimination of plasmid from the bacteria, but these are not safer for human beings. The in vivo plasmid curing studies will be crucial in developing methods to make bacteria sensitive to existing antibiotics. The interest in bacteriocins produced by LAB has increased dramatically and there are many bacteriocins that inhibit the growth of pathogenic bacteria. However, there are different kinds of pathogens in nature and bacteriocin alone can not eliminate all bacterial pathogenicity. Subsequent studies are needed to evaluate the health-promoting activity of bacteriocins. The development of new generation of antimicrobial agents is necessary in order to reduce the burden of antibiotic resistant. Biotechnological methods have to be applied to create new or multifunctional bacteriocins, so they could be widely used in medicine.

\section{Acknowledgements}

Authors acknowledge the facilities provided by Department of Biotechnology, Himachal Pradesh University, Shimla.

\section{Conflict of interest}

The authors declare no conflicts of interest relevant to this article.

\section{References}

Aastha, C.; Ziad, S.; David, C. and Helen, H. (2019). Global contributors to antibiotic resistance. J. Glob. Infect. Dis., 11(1):36-42.

Abbas, M.E.; Luo, W.; Zhu, L.; Zou, J. and Tang, H. (2010). Fluorometric determination of hydrogen peroxide in milk by using a fenton reaction system. Food Chem., 120:327-331.

Abriouel, H.; Herrmann, A.; Starke, J.; Yousif, N.M.K.; Wijaya, A.; Tauscher, B.; Holzapfel, W. and Franz, C.M.A.P. (2004). Cloning and heterologous expression of hematin-dependent catalase produced by Lactobacillus plantarum CNRZ 1228. Appl. Environ. Microbiol., 70:603-606

Alain, L.F. (2017). Antibiotics and antibiotic resistance. J. Sci. Tech. Res., 1:1-17.

Albertson, D.G. (2006). Gene amplification in cancer. Trends in Genetics, 22:447-455.

Alekshun, M.N. and Levy, S.B. (2007). Molecular mechanisms of antibacterial multidrug resistance. Cell, 128:1037-1050.

Amabile-Cuevas, C.F. (1988). Loss of penicillinase plasmids of Staphylococcus aureus after treatment with L-ascorbic acid. Mutat. Res. Lett., 207:107-9.

Amabile-Cuevas, C.F.; Piña-Zentella, R.M. and Wah-Laborde, M.E. (1991). Decreased reistance to antibiotics and plasmid loss in plasmid carrying strains of Staphylocccus aureus treated with ascorbic acid. Mutat. Res. Lett., 264:119-25.

Ammor, S.; Tauveron, G.; Dufour, E. and Chevallier, I. (2006). Antibacterial activity of lactic acid and cream samples. Bull. Environ. Contam. Toxicol., 81:422-426.

Anne-Spphie, B. and Benoit, G. (2017). Multidrug-resistant (or antimicrobial resistant) pathogens alternatives to new antibiotics. Swiss. Med. Wkly., 147:1-15.

Ayivi, R. (2020). Lactic acid bacteria: Food safety and human health applications. Dairy, 1:202-232.

Bbosa, GS.; Mwebaza, N.; Odda, J.; Kyegombe, D.B. and Ntale, M. (2014). Antibiotics/ antibacterial drug use, their marketing and promotion during the post-antibiotic golden age and their role in emergence of bacterial resistance. Health, 6:410-425. 
Bansal, D.; Sehgal, R.; Chawla, Y.; Malla, N. and Mahajan, R.C. (2006). Multidrug resistance in amoebiasis patients. Indian J. Med. Res., 124:189194

Bartlett, J.G.; Gilbert, D.N. and Spellberg, B. (2013). Seven ways to preserve the miracle of antibiotics. Clin. Infect. Dis., 56(10):1445-1450.

Blair, J.M.; Richmond, G.E. and Piddock, L.J. (2014). Multidrug efflux pumps in Gram-negative bacteria and their role in antibiotic resistance. Future Microbiol., 9:1165-1177.

Blair, J.M.A. (2015). Molecular mechanisms of antibiotic resistance. Nat. Rev. Microbiol., 13:42-51.

Bloland, P.B. (2001). Drug Resistance in Malaria, World Health Organization.

Bouanchaud, D.H. and Chabbert, Y.A. (1971). Practical effectiveness of agents curing $\mathrm{R}$ factors and plasmids. Ann. NY. Acad. Sci., 65:305-11.

Brown, D.F. and Reynolds, P.E (1980). Intrinsic resistance to beta-lactam antibiotics in Staphylococcus aureus. FEBS Letters, 122:275-278.

C.D.C. (2021). Antibiotic-resistant germs: New threats, centers for disease control and prevention. https://www.cdc.gov/drugresistance /biggest-threats.html

Carr, F. J.; Chill, D. and Maida, N. (2002). The lactic acid bacteria: A literature survey. Critical Rev. in Microbiol., 28:281-370.

Cerceo, E. (2016). Multidrug-resistant Gram-negative bacterial infections in the hospital setting: Overview, implications for clinical practice and emerging treatment options. Microb. Drug Resist., 22:412431.

Chethana, G.S.; Hari venkatesh, K.R.; Mirzaei, F. and Gopinath, S.M. (2013) Review on multidrug resistant bacteria and its implication in medical sciences. J. Biol. Sci. Opinion, 1:32-37.

Cleveland, J.; Montville, T.J.; Nes, I.F. and Chikindas, M.L. (2001). Bacteriocins: Safe, natural antimicrobials for food preservation. Int. J. Food Microbiol., 71:1-20.

Clowers, R.C. (1972). Molecular structure of bacterial plasmids. Bacterial Rev.,36:361-405.

Courvalin, P. (2006). Vancomycin resistance in Gram-positive cocci. Clin Infect. Dis., 42:25-34

Cox, G. and Wright, G.D. (2013). Intrinsic antibiotic resistance mechanisms, origins, challenges and solutions. Int. J. Med. Microbiol., 303:287-292.

Daly, C. and Davis, R. (1998). The biotechnology of lactic acid bacteria with emphasis on applications in food safety and human health. Agri. Food Sci. Finland., 7:251-265

Datta, N. and Hedges, I.L.W. (1972). Host range of R factors. J. Gen Microbiol.,70:453.

Davies, J. and Wright, G.D. (1997). Bacterial resistance to aminoglycoside antibiotics. Trends in Microbiol., 5:234-240.

De-Vuyst, L. and Leroy, F. (2007). Bacteriocins from lactic acid bacteria: Production, purification, and food applications. J. Mol. Microbiol. Biotechnol., 13: 194-199.

Drlica, K. and Malik, M. (2003). Fluoroquinolones: Action and resistance. Curr. Top. Med. Chem., 3:249-282.

Eliopoulos, G.M.; Meka, V.G. and Gold, H.S. (2004). Antimicrobial resistance to linezolid. Clin. Infect. Dis., 39:1010-1015.

Emiliano, J.Q.; Pilar, J.; Irma, C.; Jesús, T.; Javier, M. and Tomas, G. (2014) Probiotic lactic acid bacteria. Food Nutr. Sci., 5:1765-1775

Fishbain, J. and Peleg, A.Y. (2010). Treatment of Acinetobacter infections Clin. Infect. Dis., 5:179-84.

Flintoff, W.F. (1989). Acquired drug resistance. Genome, 31:447-447.
Frost, L.S. (2005). Mobile genetic elements: The agents of open source evolution. Nat. Rev. Microbiol., 3:722-732.

Fuda, C.C.S.; Fisher, J.F. and Mobashery, S. (2005). $\beta$-lactam resistance in Staphylococcus aureus: The adaptive resistance of a plastic genome. Cell Mol. Life Sci., 62:2617.

Ganzle, M.G. (2004). Reutericyclin: Biological activity, mode of action, and potential applications. Appl. Micobiol. Biotechnol., 64:326332 .

Ganzle, M.G. and Vogel, R.F. (2003). Studies on the mode of action of reutericyclin. App. Environment Microbiol., 69:1305-1307.

Gloria, C. (2021). Antibiotics special issue on the use of antibiotics in primary care. Antibiotics, 10(9):1009-1083.

Hayek, S.A. and Ibrahim, S.A. (2013). Current limitations and challenges with lactic acid bacteria: A review. Food Nutr. Sci., 4:73-87.

He X, Li. S. and Kaminskyj, S.G. (2013). Using Aspergillus nidulansto identify antifungal drug resistance mutations. Eukaryot Cell, 13:288-294.

Homann, M. (2018).Microbial life and biogeochemical cycling on land 3,220 million years ago. Nature Geosci., 11:665-671.

Hooper, D.C. (2000). Mechanisms of action and resistance of older and newer fluoroquinolones. Clin. Infect. Dis., 31:24-28.

Inuzuka, N.; Nakamura, S.; Inuzuka, M. and Tomoeda, M. (1969). Specific action of sodium dodecyl sulfate on the sex factor of Escherichia coli K$12 \mathrm{Hfr}$ strains. J. Bacteriol., 100:827-835.

Jacobs, M.R. (1999). Drug-resistant Streptococcus pneumoniae: rational antibiotic choices. Am. J. Med., 106:19-25.

Jacoby, G.A. (2009). AmpC beta-lactamases. Clin. Microbiol. Rev., 22:161-182.

Jacoby, G.A. and Munoz-Price, L.S. (2005). The new $\beta$-lactamases. New England J. Med., 352:380-391.

Junaid, A.;Qasim, A.; Rafiq and Elizabeth R. (2018). Antimicrobial resistance mechanisms and potential synthetic treatments. Future Sci. OA.,4(4).https://doi.org/10.4155/fsoa-2017-0109.

Jyoti, T.; Shrayanee, Das.; Zeeshan, F. and Saif H. (2014). Multidrug resistance: An emerging crisis. Interdiscip Perspect Infect Dis., https://doi.org/ $10.1155 / 2014 / 541340$

Kanwar, K.; Thakur, P. and Azmi, W. (2018). Use of phytochemicals as emerging strategy for control of biofilm formed by pathogens. Ann. Phytomed., 7(2):25-37.

Kanwar, K.; Pandey, R.; Gezici, S. and Azmi, W. (2019) Enzymes as competent tool for efficient management of pathogen's biofilms. Ann. Phytomed., 8(1):70-81.

Khalilzadeh, V.; Boloorsaz, M.R.; Safavi, A.; Farnia, P. and Velayati, A.A. (2006). Primary and acquired drug resistance in childhood tuberculosis. East Mediterr. Health J., 12:909-914.

Klaenhammer, T.R. (1988). Bacteriocins of lactic acid bacteria. Biochimie, 70:337-349.

Kobayashi, N.; Nishino, K. and Yamaguchi, A. (2001). Novel macrolidespecific ABC-type efflux transporter in Escherichia coli. J. Bacteriol., 183:5639-5644.

Kumar, A. and Schweizer, H.P. (2005). Bacterial resistance to antibiotics: Active efflux and reduced uptake. Adv. Drug Deliv. Rev., 57:14861513.

Kumar, S.; Mukherjee, M.M. and Varela, M.F. (2013). Modulation of bacterial Multidrug-resistance efflux pumps of the major facilitator superfamily. Int. J. Bacteriol., 2013:204141.

Kunjachan, S.; Rychlik, B.; Storm, G; Kiessling, F. and Lammers, T. (2013). Multidrug resistance: Physiological principles and nanomedical solutions. Adv. Drug Deliv. Rev., 65:1852-1865. 
Levy, S.B. (1992). Active efflux mechanisms for antimicrobial resistance. Antimicrob Agents and Chemotherapy, 36:695-703.

Levy, S.B. and Marshall, B. (2004). Antibacterial resistance worldwide: Causes, challenges and responses. Nat. Medicine, 10:122-129.

Li, A.D;, Li, I.G. and Zhang, T. (2015). Exploring antibiotic resistance genes and metal resistance genes in plasmid metal-genome from waste water treatment plants. Front. Microbiol., 6:1-11

Li, X.Z. and Nikaido, H. (2004). Efflux-mediated drug resistance in bacteria Drugs, 64:159-204.

Li, X.Z. and Nikaido, H. (2009). Efflux-mediated drug resistance in bacteria: An update. Drugs, 69:1555-1623.

Lipsitch, M. (2001). The rise and fall of antimicrobial resistance trends. Microbiol.,9:438-444.

Lipsitch, M. and Samore, M.H. (2002). Antimicrobial use and antimicrobial resistance: A population perspective. Emerg. Infec. Dis, 18:347354.

Loeffler, J. and Stevens, D.A. (2013). Antifungal drug resistance. Clin. Infect. Dis., 36:31-41.

Lushniak, B.D. (2014). Antibiotic resistance: A public health crisis. Public Health Rep., 129(4):314-316.

Maier, L.; Pruteanu, M. and Kuhn, M. (2018). Extensive impact of nonantibiotic drugs on human gut bacteria. Nature, 555:623-628.

Malouin, F. and Bryan, L.E. (1986). Modification of penicillin-binding proteins as mechanisms of beta-lactam resistance. Antimicrob. Agents and Chemother., 30:1-5.

Mariam, D.H. (2004). Effect of rpoB mutations conferring rifampin resistance on fitness of Mycobacterium tuberculosis. Antimicrob. Agents and Chemother., 48:1289-1294.

Matthews, P.R. and Stewart, P.R.Y. (1988). Amplification of a section of chromosomal DNA in methicillin-resistant Staphylococcus aureus following growth in high concentrations of methicillin. Microbiol., 134: $1455-1464$

McFadden, D.C.; Tomavo, S.; Berry, E.A. and Boothroyd, J.C. (2000) Characterization of cytochrome b from Toxoplasma gondii and $\mathrm{Q}(\mathrm{o})$ domain mutations as a mechanism of atovaquoneresistance. Mol. Biochem. Parasitology, 108:1-12.

Meek, R.W.; Hrushi, V. and Laura J.V.P. (2015). Nonmedical uses of antibiotics: Time to restrict their use?. Plos. Biol., 13:1-11.

Michelle, M.C.; Buckner, Maria, L.C. and Laura, J.V. and Piddock (2018). Strategies to combat antimicrobial resistance: Anti-plasmid and plasmid curing. Microbiol. Rev., 42:781-804.

Mobolaji, O.A. and Wuraola, F.O. (2011). Assessment of the antimicrobial activity of lactic acid bacteria isolated from two fermented maize products-ogi and kunni-zaki. Malaysian J. Microbiol., 7:124-128.

Montero, C. (2001). Intrinsic resistance of Mycobacterium smegmatis to fluoroquinolones may be influenced by new pentapeptide protein MfpA. Antimicrob. Agents and Chemother., 45:3387-3392.

Munita, J.M. and Arias, C.A. (2016). Mechanisms of antibiotic resistance. Microbiol. Spectr., 4(2):11-16.

Munshi, M.H.; Sack, D.A.; Haider, K.; Ahmed, Z.U.; Rahaman, M.M. and Morshed, M.G. (1987). Plasmid-mediated resistance to nalidixic acid in Shigella dysenteriae type. Antimicrob Agents and Chemother., 1. 330:419-21.

Nagamune, K.; Moreno, S.N.J. and Sibley, L.D. (2007). Artemisinin resistan mutants of Toxoplasma gondii have altered calcium homeostasis. Antimicrob. Agents Chemother., 51:3816-3823.
Nawaz, S.K.; Riaz S. and Hasnain S. (2009). Screening for anti-methicillin resistant Staphylococcus aureus (MRSA) bacteriocin producing bacteria. Afr. J. Biotechnol., 8:365-368.

Nehal, E.D.; Mona, M.S. and Hala, E.A. (2015). Antibacterial and plasmid curing activity of lactic acid bacteria against multidrug resistant bacteria strains. Int. J. Pharmacol., 11:114-121.

Nettles, C.G. and Susan F.B. (1993). Biochemical and genetic characteristics of bacteriocins of food-associated lactic acid bacteria. J. Food Prot., 56:338-356.

Nicoloff, H.; Perreten, V. and Levy, S.B. (2007). Increased genome instability in Escherichia coli lon mutants: Relation to emergence of multipleantibiotic-resistant (Mar) mutants caused by insertion sequence elements and large tandem genomic amplifications. Antimicrob. Agents Chemother., 51:1293-1303.

Nikaido, H. (2009). Multidrug resistance in bacteria. Ann. Rev. Biochem., 78:119-146

Nikaido, H. and Zgurskaya, H.I. (2001). AcrAB and related multidrug efflux pumps of Escherichia coli. J. Mol. Microbiol. Biotechnol., 3:215218 .

Nishimura, Y.; Ishlbashi, M.; Meynell, E. and Hirota, Y. (1967). Specific piliation directed by a fertility factor and a resistance factor of Escherichia coli. J. Gen. Microbiol., 49:89-98.

O'Neill (2014). Tackling a crisis for the health and wealth of nations. a review on Antimicrobial resistance. World Health Organization. London, UK.

Orozco, E.; Lopez, C. and Gomez, C. (2002). Multidrug resistance in the protozoan parasite Entamoeba histolytica. Parasitology International, 51:353-359.

Ouellette, M.; Egare, D.L. and Papadopoulou, B. (2001). Multidrug resistance and $\mathrm{ABC}$ transporters in parasitic protozoa. J. Mol. Microbiol. Biotechnol., 3:201-206.

Oyetayo, V.O.; Adetuyi, F.C. and Akinyosoye, F.A. (2003). Safety and protective effect of Lactobacillus acidiphilus and Lactobacillus casei used as probiotic agent in vivo. Afr. J. Biotechnol., 2:448-452.

Pa, L. (2002). Cellular impermeability and uptake of biocides and antibiotics in Gram-positive bacteria and mycobacteria. J. Applied. Microbiol., 92:46-54.

Payne, D.J.; Gwynn, M.N; Holmes, D.J. and Pompliano, D.L. (2007). Drugs for bad bugs: Confronting the challenges of antibacterial discovery. Nat. Rev. Drug Discov., 6:29-40.

Pfaller, M.A. (1997). Inducible amp C beta-lactamase producing gramnegative bacilli from blood stream infections: Frequency, antimicrobial susceptibility, and molecular epidemiology in a national surveillance program (SCOPE). Diagnost. Microbiol. Infect. Dis., 28:211-219.

Piekarska, K. (2012). Prevalence of qnr genes in clinical Entero bacteriaceae non-susceptible to fluoroquinolone in Poland. Medycyna Doswiadczalna I. Mikrobiologia., 64:211-219.

Poirel, L. (2001). Characterization of class 1 integrons from Pseudomonas aeruginosathat contain the blaVIM-2 carbapenemhydrolyzing $\beta$-lactamase gene and of two novel aminoglycoside resistance gene cassettes. Antimicrob. Agents Chemother., 45:546552 .

Poole, K. (2005). Efflux-mediated antimicrobial resistance. J. Antimicrob. Chemother., 56:20-51.

Poole, K. (2007). Efflux pumps as antimicrobial resistance mechanisms. Ann. Med., 39:162-176.

Popêda, M.; P $^{3}$ uciennik, E. and Bednarek, A.K. (2014). Proteins in cancer resistance. Postêpy Higieny i Medycyny Do'swiadczalnej., 68: 616-632. 
Rahube, T.O.; Romain, M.; Andrew, S.; Yuan-Ching, T.; Roger, M.; Lyne, S.; Peter, D.; David, R.L.and Edward, T. (2016).Persistence of antibiotic resistance and plasmid-associated genes in soil following application of sewage sludge and abundance on vegetables at harvest. Can. J. Microbiol., 62:600-607.

Raj, A. (2012). Antibiotic resistance, plasmid and RAPD profiles of multidrug-resistant Escherichia coli form bacteria isolated form sewage samples of Ghaziabad city, India. Environ. RES. Technol., 2:318-324.

Ramesh, P.M.; Halami and Chandrashekar, A. (2000). Ascorbic acid-induced loss of a pediocin-encoding plasmid in Pediococcus acidilactici CFR K7 A. J Microbiol Biotechnol., 16:695-697.

Ray, S.; Das, S. and Suar, M. (2017). Molecular mechanism of drug resistance, In: Arora, G, Sajid A, and Kalia VC (eds) Drug Resistance in Bacteria, Fungi, Malaria, and Cancer. Cham: Springer International Publishing. pp:47-110.

Read, A.F. and Woods, R.J. (2014). Antibiotic resistance management. Evol Med. Public Health, 147:(1)121-131.

Riaz, S.; Nawaz, S.K. and Hasnain, S. (2010). Bacteriocins produced by L. fermentum and L. acidophilus can inhibit cephalosporin resistant E. coli. Braz. J. Microbiol., 41:643-648.

Rolain, J.M. (2016). Do we need new antibiotics?. Clin. Microbio. Infect., 22:408-415.

Rosas, S.B.; Calzolari, A. and La Torre, J.L. (1983). Involvement of a plasmid in Escherichia coli envelope alterations. J. Bacteriol., 155:402-6.

Ross, J.I. (1998). 16S rRNA mutation associated with tetracycline resistance in a Gram-positive bacterium. Antimicrob. Agents Chemother., 42:1702-1705.

Rotimi, V.O.; Duerden, B.I. and Hafiz, S. (1981). Transferable plasmid mediated antibiotic resistance in Bacteroides. J. Med. Microbiol., 14:359-70.

Rustam, I.A. (2010). A brief history of the antibiotic era: Lessons learned and challenges for the future. Front. Microbiol., https://doi.org/ $10.3389 /$ fmicb. 2010.00134

San, D. and La, J (1990). Plasmid-mediated 4-quinolone resistance. Am. Soc. Microbiol., 34:681-684.

Schelz, Z; Molnar, J. and Hohmann, J. (2006). Antimicrobial and antiplasmid activities of essential oils. Fitoterapia, 77:279-285

Sharma, S.K. and Mohan, A. (2006). Multidrug-resistant tuberculosis: A menace that threatens to destabilize tuberculosis control. Chest., 130:261-272.

Singh, V. (2013). Antimicrobial resistance in microbial pathogensand strategies for combating them: Science, technology and education. Formatex Research Center, 1:291-296.

Sköld, O. (2001). Resistance to trimethoprim and sulfonamides. Veterinary Res., 32:261-273.

Solomon, S.L. and Oliver, K.B. (2014). Antibiotic resistance threats in the United States: Stepping back from the brink. American Family Physician, 89:938-941.

Soomro, A.H.; Masud, T. and Anwaar, K. (2002). Role of lactic acid bacteria (LAB) in food preservation and human health-A review. Pak. J. Nutr., 1:20-24.

Spellberg, B. and Gilbert, D.N. (2014). The future of antibiotics and resistance: A tribute to a career of leadership by John Bartlett. Clin. Infect. Dis., 59:S71-S75

Stokes, H.W. and Gillings, M.R. (2011). Gene flow, mobile genetic element and the recruitment of antibiotic resistance genes into Gramnegative pathogens. FEMS Microbiol Rev., 35(5):790-819.
Strasfeld, L. Chou and S. (2010). Antiviral drug resistance: mechanisms and clinical implications. Infect. Dis. Clinic North America, 24:413437.

Subhashree, B.; Niranjana Sri, S.; Harini, C.; Gagana, R.; Ganesh, P.; Arun, K.; Siva Bala, S.; Anbazhagan, V. and Saisubramanian, N. (2019). Sub lethal levels of platinum nanoparticle cures plasmid and in combination with carbapenem, curtails carbapenem resistant Escherichia coli. Sci. Rep., 9:5305

Tagg, J.R.; Dajani, A.S. and Wannamaker, L.W. (1976). Bacteriocins of grampositive bacteria. Bacteriol. Rev., 40:22-756.

Tenover, F.C. (2006). Mechanisms of antimicrobial resistance in bacteria. The American J. Med., 119:3-10.

Tomoeda, M.; Inuzuka, M.; Kubo, N. and Nakamura, S. (1968). Effective elimination of drug resistance and sex factors in Escherichia coli by sodium dodecyl sulphate. J. Bacteriol., 95:1078-1 089.

Tran, J.H. and Jacoby, G.A. (2002). Mechanism of plasmid-mediated quinolone resistance. Proc. Natl. Acad Sci., 99:5638-5642.

U.S. Federal Register (U.S. Food and Drug Administration) (1988). Nisin preparation: Affirmation of GRAS status as a direct human food ingredient. 21 CFR Part 184, Fed. Reg., 53:11247-11251.

Van Boeckel, T.P.; Brower, C. and Gilbert, M. (2015). Global trends in antimicrobial use in food animals. Proc. Natl. Acad Sci. U S A., 112 (18):5649-5654.

Vengadesh, L.; Kok-Gan, C. and Learn-Han, L. (2015). Insight of traditional plasmid curing in vibrio species. Food Microbial., 6:735.

Ventola, C.L. (2015). The antibiotic resistance crisis: Part 1: Causes and threats. P. T. J. Pharmacy and Therapeutics, 40(4):277-283.

Vivas, R. (2019). Multidrug-resistant bacteria and alternative methods to control them: An overview. Microb. Drug Res., 25:890-908.

Vyvyan, S.; Edges, R.W.H. and Naomi, D. (1972). Two modes of 'curing' transmissible bacterial plasmids. J. General Microbiol., 70:443-452.

Waxman, D.J. and Strominger, J.L. (1983). Penicillin-binding proteins and the mechanism of action of beta-lactam antibiotics. Annual Rev. Biochem., 52:825-869.

Wee, Y.J.; Kimm, J.N. and Ryu, H.W. (2006). Biotechnological production of lactic acid and its recent applications. Food Technol. Biotechnol., 44:163-172.

Weigel, L.M. (2003). Genetic analysis of a high-level vancomycin-resistant isolate of Staphylococcus aureus. Science, 302:1569-1571.

Wielders CL (2001). In vivo transfer of mecA DNA to Staphylococcus aureus [corrected]. Lancet, 357:1674-1675.

Wilson, P. (2003). Linezolid resistance in clinical isolates of Staphylococcus aureus. J. Antimicrob. Chemother., 51:186-188.

World Health Organization (2014). Antimicrobial Resistance Global Report on Surveillance.

World Health Organization, Geneva, Switzerland (2014). Antimicrobial Resistance Global Report on Surveillance.

Wu, C.P.; Ohnuma, S. and Ambudkar, S.V. (2011). Discovering natural product modulators to overcome multidrug resistance in cancer chemotherapy. Curr. Pharmaceutical Biotechnol., 12:609-620.

Xian-Zhi Li and Hiroshi N. (2009). Efflux-mediated drug resistance in bacteria: An update. Drugs, 69:1555-623.

Yang, E.; Fan, L.; Jiang, Y.; Doucette, C. and Fillmore, S. (2012). Antimicrobial activity of bacteriocin producing lactic acid bacteria isolated from cheeses and yogurts. AMB Express, 2:1-12. 